\title{
The Golden Rule of Grading: Being Fair
}

\author{
Brian J. Glenn, Oxford University
}

Here is a typical scene. After two teaching assistants, one experienced and one new, hand back the first graded assignment in the fall, the experienced TA gets a few students coming in to ask about how they can improve their work. The students may be upset, but they usually are not angry at the grader. They ask what they can do to improve their performance next time. Meanwhile, the new TA has a line of angry students coming in to argue that the grading wasn't fair. It happens every fall, and new TAs find themselves wondering why they are dealing with such an angry crowd when the more experienced ones are not. The reason new TAs hear the complaint about unfair grading far more often than senior ones is that experienced graders tend to follow four important rules. This article may help new teaching assistants from having to learn these rules the hard way. If TAs take this advice seriously, they will find teaching and grading far more pleasant, and their students will be more satisfied as well.

\section{The Four Rules of Being a Fair Grader}

1. Set clear standards, and make them known in advance.

2. Apply the same standards to everyone.

3. Stand firm when you are right, admit it when you are wrong.

4. Take your students seriously.

These rules are a package deal, in that each supports the other. After a while, you will find that you follow them naturally. The best part about these rules is that they are the easiest ones you can follow. Any time you veer off the path set by these

Brian J. Glenn is a graduate student in politics at St. Antony's College, Oxford. rules, you make more work for yourself.

\section{Setting Clear Standards and Making Them Known in Advance}

A common complaint in political science is that so much of what we do is subjective, and this makes grading difficult. The way to make grading easier is to turn a seemingly subjective assignment into a more objective one. The trick is to make your standards known early on and use them as a central part of your grading criteria.

\section{Use of Course Themes}

First, search for underlying course themes. Every class is built on a group of themes, or analytical lenses, which are used to explain the subject. The key is to ensure that students are using those analytic tools in their work. In other words, when you are grading, ask yourself, "Did the student use the tools available to him or her in answering the question?" A common complaint of students is that the grader has a bias, and that this taints the grades. If you focus on whether or not students used the tools available to them when you write your comments, this complaint rings hollow. Under this system, there is no right or wrong answer, there are simply some answers that are better supported than others are. The focus then turns back to where it belongs - on the paper itself.

\section{Quality of Writing}

The second standard is the quality of the writing. Having a good argument is only half the picture, the other half is the author's ability to convey it. A paper must be well written and it must be clear. It should begin with a thesis paragraph, in which the author lays out the argument and how it will be supported. The body of the paper must then answer the question the author poses. It should end with a substantive conclusion. Grammar matters, since poor writing detracts from the argument, and the grade should reflect this. Students will improve the quality of their writing if they know their grades depend on it.

\section{Answering the Question}

Finally, the assignment must answer the question. A big mistake some students make is answering their own question instead of the one they are given. A well-written, strongly-argued paper does not deserve a good grade if it fails to complete the assignment; the assignment is determined by the people making it, not the ones answering it.

In the review section before the assignment is due, go over your standards. Explicitly tell the students what is expected in terms of writing quality, substance, and answering the question. Take five to ten minutes to explain your grading criteria, especially when there are a lot of freshmen and sophomores in the class. What may seem obvious to you may be news to them.

The biggest favor you can do for your students is to set a high standard up front and hold them to it. The sooner students learn that success comes from good performance, the better they will do not only in their academic careers, but all throughout life. If we, as teachers, do not hold our students to high standards, we are not doing them any favors, since their future employers will not be so understanding. 


\section{Applying the Same Standards to Everyone}

It is a natural instinct to want to give the students who are good in section the benefit of the doubt when you grade their papers. Unfortunately, this violates the concept of fairness. Some students are good at conveying concepts orally and are aggressive in section. Then there are the quiet ones, or the ones who are distracted. But those quiet students may actually be the brightest, and the distracted students may have other serious (and legitimate) concerns on their minds. In any case, a written assignment can only be graded on what the student writes. As hard as it is to do, when you sit down to grade, flip over the cover page without looking at the name. What needs to be assessed is the student's performance on the assignment, judged by the standards you have set and made known to the students, and nothing more.

Of course section participation should count as well. This is why most professors give teaching assistants discretion over 5 to $10 \%$ of the final grades. When awarding this percentage, you should to grade only section performance, leaving out the student's written performance. The key is to be consistent: grade only on the component you claim to be testing. If you include favoritism or perceptions of students from section in your grading of writing assignments, you are not being fair to them, since you are grading them by standards other than those relevant to the assignment.

\section{Being Firm When You Are Right, Admitting it When You Are Wrong}

The biggest misconception many TAs have is that the best way to avoid upsetting students is by giving in to them when they complain about their grade. This is wrong. In fact, just the opposite is true. If you want to keep students from complaining, grade properly the first time and then hold to it. TAs quickly get reputations: give in once when you should not have, and there will be twenty students lining up outside your door looking for the same.
Remember that what students really want is to be treated fairly. If you grade earnestly and let them know your standards before hand, the only thing left is to explain where they were not up to standard. The trick is to take some time with your comments, remembering that while there is often no correct answer, what you are looking for is a well-argued paper based upon the analytical tools used in the course. When you spell out your reasoning for giving the grades you do, you will find that very few students come to complain. They may come to ask how they can do better next time, however, and this is a great opportunity for you to teach them something useful.

The beauty of this system is that the only place for you to err is getting a fact wrong. If a student comes in to complain that you made an error, and you really did make one, admit it and change the grade accordingly. Make it clear, however, that you are changing the grade on the merits of the paper, not on the student's argument. If you are fair in the first assignment, you will quickly develop a reputation that will follow you from course to course. Students will know when to come see you and when they shouldn't bother.

\section{Taking Your Students Seriously}

I cannot stress enough that you must always take your students seriously. To them, you are an authority figure, and they will not come to you unless they feel they have something important to discuss. If you do not take your students seriously, one of at least three problems can occur. First, remember that you are an authority figure first and foremost, even if you consider the students your friends. Young TAs, who were just undergraduates a year or two before, may see their students as peers, but students will still see the teaching assistant as a teacher. Chum around once the course is over and the grades are in, but stay detached until then. The last thing you want to do is reduce your authority in the eyes of your students. Second, do not ever use sarcasm, which can be easy to do when a student writes something that you think sounds stupid. It may be innocuous when you write it on a peer's paper, but it can be devastating to an undergraduate. Treat ev-

ery paper as if the student put a great deal of effort into it, even if you do not think he or she did. Keep your comments helpful and professional. Third, and finally, when you are writing comments or communicating with students of the opposite sex, be very careful in how you use humor, and avoid off-color humor completely. It may seem funny to you in the context of the moment, but it might not seem so funny when you have to explain it to a dean or department chair when a student complains.

\section{Fairness-The Golden Rule}

Students want to be treated fairly. Even subjective grading can be done in a fairly objective fashion if the standards are made known in advance. Your students will respect you more if they think you have taken them seriously; in fact, they will return the favor. The best part about all of this is that these rules are the easiest ones to follow. By making the standards known in advance, in effect you have created an answer key, and it makes grading much easier. Students also quickly come to learn that they should only approach you when they think you made an honest error, or when they want to learn how to do better.

One of the biggest compliments you can get as a teaching assistant is that you are fair. Following the advice given in this article can help you deserve such a compliment. 